\title{
Patient Self-Perceptions of Swallowing Difficulties as Compared to Expert Ratings of Videofluorographic Studies
}

\author{
Ruiying Ding ${ }^{a}$ Jeri A. Logemann ${ }^{b}$ \\ a Department of Communication Sciences and Disorders, University of Wisconsin-Whitewater, Whitewater, Wisc., \\ and ${ }^{b}$ Department of Communication Sciences and Disorders, Northwestern University, Evanston, III., USA
}

\section{Key Words}

Deglutition disorder · Self-perception • Videofluorography

\begin{abstract}
Background/Aims: Research investigating the relationship between subjective and objective assessment of dysphagia in patients with various diagnoses has yielded conflicting results. The goal of this study is to investigate the reliability of patient self-perceptions of swallowing difficulties compared to expert ratings of videofluorographic studies considering three medical diagnostic categories: neurological disorders, structural deficits and general medical diagnoses. Methods: One hundred and three patients who were referred for videofluorographic swallow evaluation were included in the study. Face-to-face interviews with patients were conducted before their videofluorographic studies. The correlation between patient self-perceptions and expert ratings of the videofluorographic studies was established by comparing the results of patients' self-reports with the results of the videofluorographic studies. Results: The correlation between patient self-perceptions of swallowing difficulties and expert ratings of the videofluorographic studies varied greatly depending on the patients' medical diagnoses. The correlation was mild in patients with neurological disorders, moderate in patients with structural defi-
\end{abstract}

cits and high in patients with general medical diagnoses. Conclusion: The results of this study demonstrated that patient self-perceptions of swallowing difficulties should be used as one of the criteria, but not the only one, in making referrals for further swallowing evaluation, especially in patients with neurological disorders.

Copyright $\odot 2008$ S. Karger AG, Basel

In many medical settings, patient complaints of swallowing difficulty are used as a primary indicator for further swallowing evaluation regardless of the patient's medical diagnosis. Research investigating the relationship between subjective and objective assessment of dysphagia in patients with various diagnoses has yielded conflicting results. Some research studies have found that patient self-perceptions of swallowing difficulty did not correlate with videofluorographic findings [14]. Most patients with primary brain tumors were unaware of their swallowing difficulties while their videofluorographic studies showed moderate to moderately severe impairment in swallowing function [1]. Patients treated with diverticulectomy and cricopharyngeal myotomy for Zenker's diverticulum demonstrated more objective radiographic abnormalities on barium esophagrams than their subjective complaints of dysphagia 
would suggest [2]. In a study of patients with duodenal ulcerations treated with proximal selective vagotomy, no differences were found in manometric examination of the lower esophageal sphincter between patients with and without complaints of dysphagia [3]. In another study, patients who had had a stroke and demonstrated silent aspiration on videofluoroscopy had fewer subjective complaints of dysphagia than seen on objective evaluation [4].

On the other hand, a number of studies have found a relationship between subjective complaints of dysphagia and objectively assessed swallowing function [5-8]. One study found that a swallowing questionnaire was predictive of swallowing function assessed with the modified barium swallow in a group of patients with progressive supranuclear palsy [5]. Studies of patients with Sjögren's syndrome indicated that those with greater subjective ratings of dysphagia had more abnormalities in the pharynx and esophagus during the swallow as measured with videofluoroscopy or manometry [6, 7]. In a study investigating swallowing function and perception of dysphagia in patients with head and neck cancer, patients with complaints of dysphagia were found to demonstrate significantly worse swallow function as indicated by lower oropharyngeal swallow efficiency, longer transit times, larger residues, and more swallows with aspiration than patients with no complaints [8].

The sample size of all the studies ranged from 16 to 132 patients with the majority of the studies including smaller numbers of subjects (18-30) [1,2,4-7, 9, 10]. All studies were concentrated on one medical diagnosis category. All studies employed a measure of subjective complaints of swallowing difficulty with an objective measure of swallowing function, including videofluoroscopy, manometry or esophagram. There have been no studies to date that have investigated the relationship between subjective perception and objective measurement of swallowing difficulty in patients from a variety of medical diagnostic categories. The purpose of this present study was to investigate the correlation between patient self-perceptions of swallowing difficulties and expert ratings of videofluorographic studies using medical diagnosis as a factor. A patient's subjective perception of swallowing difficulty relies heavily on an intact sensory system, including the sensory receptors, peripheral and central sensory pathways, and it will be affected differently based on various levels of sensory system damage. It is hypothesized that patients with a diagnosis of neurological disorders will be less reliable in self-perception of swallowing difficulty than patients with a diagnosis of structural deficits or patients with general medical diagnoses. The results will tell us whether patient self-perception of swallowing difficulties is a reliable indicator for further diagnostic testing in swallowing function in patients with a range of medical diagnoses.

\section{Subjects and Methods}

Subjects

A total of 103 patients with various medical diagnoses who were referred for videofluorographic evaluation of oropharyngeal swallowing because of clinical need were included in the study. Informed consent was obtained from all subjects and the study was approved by the institutional review board of the human subjects protection committee of Northwestern University. All patients were able to answer simple questions reliably. The 103 patients and their specific medical diagnoses are reported in table 1. All of the medical diagnoses are put into one of the three major medical diagnostic categories: neurological disorders (e.g. stroke, Parkinson's disease), structural deficits (e.g. head and neck cancer, Zenker's diverticulum), and general medical disorders (e.g. respiratory disease, bone diseases and surgery). Gender and average age of the patients are also reported in the same table. For patients who had multiple medical diagnoses, the primary diagnosis was used to assign patients into one of the three diagnostic categories.

\section{Procedures}

The format of the study was face-to-face interviews with the patients before their videofluorographic studies. Patients were asked 4 research questions. (1) Have you noticed any swallowing difficulty? Yes or no. (2) Who first noticed the swallowing difficulty? Medical community (including doctor or nurse), self or family member or no perceived swallowing difficulty. (3) Where do you think the swallowing problem is located? No swallowing problem, oral (mouth area) or pharyngeal (throat area), or both. (4) How severe do you think the swallowing problem is? No swallowing problem, mild, moderate or severe. According to patients' self-reports, swallowing disorders were classified as present or absent. The location of the swallowing disorders was described as none, oral (if patients reported mouth area swallowing problems only), pharyngeal (if patients reported throat area swallowing problems only), or both (if patients reported both mouth and throat area swallowing problems). The severity of swallowing disorders was rated as mild, moderate or severe according to each patient's self-report.

A small percentage of patients answered the first question by indicating that they have swallowing problems but answered the third and fourth questions regarding the location and severity of their swallowing problems by indicating that they do not have a swallowing problem. One hypothesis is that these patients were told by medical staff or family members that they have swallowing problems and indicated so when asked about the presence of swallowing problems. When asked specifically about the location or severity of the swallowing problems, however, they were unable to provide that information. 
Table 1. All patients' specific medical diagnoses and the medical diagnostic category into which they belong

\begin{tabular}{|c|c|c|c|c|}
\hline Medical diagnosis & $\begin{array}{l}\text { Number of } \\
\text { patients }\end{array}$ & Total & $\begin{array}{l}\text { Age }(\text { mean } \pm S D) \\
\text { years }\end{array}$ & $\begin{array}{l}\text { Male: } \\
\text { female }\end{array}$ \\
\hline Neurological disorders & & 30 & $62.9 \pm 18.2$ & $75: 25$ \\
\hline Stroke of various locations & 16 & & & \\
\hline Parkinson's disease & 7 & & & \\
\hline Brain cancer & 2 & & & \\
\hline Multiple sclerosis & 3 & & & \\
\hline Amyotrophic lateral sclerosis & 1 & & & \\
\hline Myasthenia gravis & 1 & & & \\
\hline Structural deficits & & 24 & $59.1 \pm 13.7$ & $53: 47$ \\
\hline Head and neck cancer & 15 & & & \\
\hline Zenker's diverticulum & 4 & & & \\
\hline Thyroid disease & 3 & & & \\
\hline Vocal fold paralysis & 2 & & & \\
\hline General medical diagnoses & & 49 & $64.9 \pm 14.1$ & $55: 45$ \\
\hline Respiratory diseases & 14 & & & \\
\hline Bone diseases and surgery & 9 & & & \\
\hline Heart disease & 5 & & & \\
\hline Breast cancer & 3 & & & \\
\hline Abdominal surgery & 3 & & & \\
\hline Lung cancer & 3 & & & \\
\hline Liver disease & 2 & & & \\
\hline Lymphoma & 2 & & & \\
\hline Diabetes & 2 & & & \\
\hline Renal failure & 2 & & & \\
\hline Pancreatic cancer & 1 & & & \\
\hline Leukemia & 1 & & & \\
\hline Urinary tract infection & 1 & & & \\
\hline Lupus & 1 & & & \\
\hline
\end{tabular}

Table 2. Grading scale for videofluorographic studies of swallowing function

\begin{tabular}{ll}
\hline Normal & $\begin{array}{l}\text { Normal study; no evidence of oral or pharyngeal } \\
\text { impairment }\end{array}$ \\
\hline $\begin{array}{l}\text { Mild } \\
\text { swallowing } \\
\text { difficulty }\end{array}$ & $\begin{array}{l}\text { No aspiration; possible oral stage dysphagia; } \\
\text { adequate pharyngeal contraction with possible } \\
\text { minimal pooling in valleculae and/or pyriform } \\
\text { sinuses; mildly delayed pharyngeal swallow } \\
(3-5 \text { s) }\end{array}$ \\
\hline $\begin{array}{l}\text { Moderate } \\
\text { swallowing } \\
\text { difficulty }\end{array}$ & $\begin{array}{l}\text { Trace aspiration (no silent aspiration) or laryn- } \\
\text { or pyriform sinuses and/or coating of pharyngeal }\end{array}$ \\
& $\begin{array}{l}\text { walls after swallowing, resulting in risks of aspi- } \\
\text { ration; moderately delayed pharyngeal swallow } \\
\text { (6-10 s) }\end{array}$ \\
\hline $\begin{array}{l}\text { Severe } \\
\text { swallowing } \\
\text { difficulty }\end{array}$ & $\begin{array}{l}\text { Consistent aspiration (may be silent); severe } \\
\text { pooling in valleculae and/or pyriform sinuses; } \\
\text { severely delayed pharyngeal swallow (20-30 s); } \\
\text { does not exhibit necessary cognitive skills and/or } \\
\text { physiologic support for oral feeding }\end{array}$ \\
\hline
\end{tabular}

The videofluorographic studies were performed at the radiology suite with a fluoroscopic unit (Siregraph, Siemens AG Medical Solutions, Germany). At least 3 consistencies of material were used in the videofluorographic studies: thin liquid barium (as close to water as possible), paste barium (chocolate pudding mixed with Esophatrast) and material requiring mastication (a cookie coated with pudding mixed with Esophatrast). At least two swallows of each material were given in the following amounts: $1,3,5$, and $10 \mathrm{ml}$ and a cup of thin liquid; $1 / 3$ teaspoon of pudding, and a fourth of a small Lorna Doone cookie coated with barium. Patients were seated initially in the lateral plane and the vocal tract was viewed laterally. When the desired number of swallows of various materials had been completed in the lateral view, the patient could be turned and viewed in the posterior-anterior plane as needed. The posterior-anterior view was helpful in looking at asymmetries in function, particularly of the pharyngeal walls and vocal folds, and in viewing residues of material in the valleculae and in one or both pyriform sinuses.

A speech language pathologist who was unaware of the purpose of the study judged the presence, location and severity of the swallowing difficulty based on the results of the videofluoroscopic study. A swallowing difficulty was judged to be present if one of the swallowing disorders was diagnosed. The location of the swallowing difficulty was judged to be oral if only oral swallow- 
Table 3. Intrajudge reliability between two rating sessions in identifying presence, location and severity of swallowing disorders in videofluorographic studies

\begin{tabular}{lllll}
\hline & $\begin{array}{l}\text { First } \\
\text { session }\end{array}$ & $\begin{array}{l}\text { Second } \\
\text { session }\end{array}$ & Cramer's V & $\begin{array}{l}\text { Prob- } \\
\text { ability }\end{array}$ \\
\hline $\begin{array}{l}\text { Presence of swallowing } \\
\text { difficulty }\end{array}$ & & & & \\
$\quad \begin{array}{l}\text { Present } \\
\text { No difficulty }\end{array}$ & 0.64 & 0.64 & & 0.001 \\
$\begin{array}{l}\text { Location of swallowing } \\
\text { difficulty }\end{array}$ & 0.36 & 0.36 & & \\
$\quad$ Oral & 0 & 0 & 1 & $<0.001$ \\
$\quad \begin{array}{l}\text { Pharyngeal } \\
\text { Both }\end{array}$ & 0.55 & 0.55 & & \\
$\quad$ No difficulty & 0.09 & 0.09 & & \\
Severity of swallowing & 0.36 & 0.36 & & \\
difficulty & & & & \\
$\quad$ Mild & & & 0.89 & \\
Moderate & 0.18 & 0.18 & & \\
$\quad$ Severe & 0.27 & 0.36 & & \\
$\quad$ No difficulty & 0.18 & 0.09 & & \\
\hline
\end{tabular}

ing disorders such as delayed oral initiation or reduced tongue strength were present. The location of swallowing difficulty was judged to be pharyngeal if only pharyngeal swallowing disorders such as reduced laryngeal elevation or reduced tongue base retraction were present. The location of swallowing difficulty was judged to be both oral and pharyngeal if both oral and pharyngeal disorders such as reduced tongue manipulation and reduced laryngeal closure were present. The severity of swallowing difficulty was judged using a grading scale adapted from the study of Newton et al. [1] (table 2). To assess the intrajudge reliability, the same reviewer rated the presence, location and severity of the swallowing disorders in 10 randomly chosen videofluorographic studies (table 3). A second reviewer who was unaware of the purpose of the study also rated the presence, location and severity of the swallowing disorders in the same 10 patients and the interjudge reliability results are reported in table 4 .

\section{Data Analysis}

Cramer's V correlation was used to determine the degree of relationship between patient self-perceptions of swallowing difficulty and expert ratings of the videofluorographic studies. Cramer's $\mathrm{V}$ test is a statistical test that measures the strength of correlation between two sets of categorical data [11]. It yields scores ranging from 0 to 1 , with 1 indicating a perfect correlation and 0 indicating no correlation. For this study, the correlation was considered mild when Cramer's V was between 0.1 and 0.3 ; it was considered moderate when Cramer's $\mathrm{V}$ was between 0.301 and 0.5 , and it was considered high when Cramer's V was between 0.501 and 1.0. Three Cramer's V tests were performed on the presence, location and severity of swallowing difficulties comparing patient self-perceptions and expert ratings of the videofluorographic studies considering three medical diagnostic categories.
Table 4. Interjudge reliability between two raters in identifying presence, location and severity of swallowing disorders in videofluorographic studies

\begin{tabular}{lllll}
\hline & $\begin{array}{l}\text { First } \\
\text { rater }\end{array}$ & $\begin{array}{l}\text { Second } \\
\text { rater }\end{array}$ & Cramer's V & $\begin{array}{l}\text { Prob- } \\
\text { ability }\end{array}$ \\
\hline $\begin{array}{l}\text { Presence of swallowing } \\
\text { difficulty }\end{array}$ & & & & \\
$\quad \begin{array}{l}\text { Present } \\
\text { No difficulty }\end{array}$ & 0.64 & 0.64 & & 0.001 \\
$\begin{array}{l}\text { Location of swallowing } \\
\text { difficulty }\end{array}$ & 0.36 & 0.36 & & \\
$\quad$ Oral & 0 & 0 & 1 & $<0.001$ \\
$\quad \begin{array}{l}\text { Pharyngeal } \\
\text { Both }\end{array}$ & 0.55 & 0.55 & & \\
$\quad$ No difficulty & 0.09 & 0.09 & & \\
Severity of swallowing & 0.36 & 0.36 & & \\
difficulty & & & & \\
$\quad$ Mild & & & 0.85 & \\
Moderate & 0.18 & 0.18 & & \\
$\quad$ Severe & 0.27 & 0.36 & & \\
$\quad$ No difficulty & 0.18 & 0.09 & & \\
\hline & 0.37 & 0.37 & & \\
\hline
\end{tabular}

\section{Results}

Swallowing problems were reported in $85 \%$ of the patients regardless of medical diagnosis prior to videofluorographic studies. For the location of swallowing difficulty, $4 \%$ of the patients indicated oral area swallowing problems, 55\% indicated pharyngeal area swallowing problems, $4 \%$ indicated both oral and pharyngeal area swallowing problems and $37 \%$ of the patients indicated no swallowing problem. The severity of dysphagia complaints ranged from no swallowing problem ( $35 \%$ of the patients) to mild ( $27 \%$ of the patients) to moderate (23\% of the patients) to severe (15\% of the patients). Over $54 \%$ of the patients noticed a swallowing problem themselves, followed by the medical community (34\%). In only a small percentage of patients (8.7\%) did family members first notice a swallowing problem. Cramer's $\mathrm{V}$ value ranged from 0.425 to 0.597 between patient perceptions of swallowing difficulties and expert ratings of the videofluorographic studies regardless of medical diagnoses (table 5). The correlation measures for the presence, location and severity of the swallowing problems were all significant $(\mathrm{p}<0.001)$.

When the correlation between patient self-perceptions of swallowing difficulties and expert ratings of the videofluorographic studies was further investigated using medical diagnosis as a factor, different correlation pat- 
Table 5. Relationship between percentages of all patient self-perceptions of swallowing difficulties and expert ratings of the videofluorographic studies (VFG) according to presence, location and severity of the swallowing difficulty

\begin{tabular}{lllll}
\hline & $\begin{array}{l}\text { Self-per- } \\
\text { ception }\end{array}$ & VFG & Cramer's V & $\begin{array}{l}\text { Prob- } \\
\text { ability }\end{array}$ \\
\hline $\begin{array}{l}\text { Presence of swallowing } \\
\text { difficulties }\end{array}$ & & & & \\
$\quad$ Present & 0.85 & 0.86 & & $<0.001$ \\
$\quad$ No difficulty & 0.15 & 0.14 & & \\
Location of swallowing & & & & \\
difficulties & & & 0.425 & $<0.001$ \\
$\quad$ Oral & 0.04 & 0.06 & & \\
$\quad$ Pharyngeal & 0.55 & 0.58 & & \\
$\quad$ Both & 0.04 & 0.08 & & \\
$\quad$ No difficulty & 0.37 & 0.28 & & \\
Severity of swallowing & & & 0.001 \\
difficulties & & 0.31 & & \\
$\quad$ Mild & 0.27 & 0.353 & \\
$\quad$ Moderate & 0.23 & 0.18 & & \\
$\quad$ Severe & 0.15 & 0.20 & & \\
$\quad$ No difficulty & 0.35 & 0.31 & & \\
\hline
\end{tabular}

Table 6. Relationship between percentages of patient self-perceptions of the presence of swallowing difficulties and expert ratings of the videofluorographic study (VFG) considering three diagnostic categories

\begin{tabular}{|c|c|c|c|c|c|}
\hline Diagnosis & $\begin{array}{l}\text { Presence of } \\
\text { swallowing } \\
\text { difficulties }\end{array}$ & $\begin{array}{l}\text { Self-per- } \\
\text { ception }\end{array}$ & VFG & $\begin{array}{l}\text { Cramer's } \\
\text { V }\end{array}$ & $\begin{array}{l}\text { Prob- } \\
\text { ability }\end{array}$ \\
\hline \multirow[t]{2}{*}{ Neurological } & present & 0.57 & 0.67 & \multirow[t]{2}{*}{0.238} & \multirow[t]{2}{*}{0.193} \\
\hline & no difficulty & 0.43 & 0.33 & & \\
\hline \multirow[t]{2}{*}{ Structural } & present & 0.71 & 0.58 & \multirow[t]{2}{*}{0.573} & \multirow[t]{2}{*}{0.005} \\
\hline & no difficulty & 0.29 & 0.42 & & \\
\hline \multirow[t]{2}{*}{ General } & present & 0.67 & 0.65 & \multirow[t]{2}{*}{0.864} & \multirow[t]{2}{*}{$<0.001$} \\
\hline & no difficulty & 0.33 & 0.35 & & \\
\hline
\end{tabular}

terns appeared. The correlation between patient self-perceptions of the presence of swallowing difficulties and expert ratings of the videofluorographic studies for the three medical diagnostic categories is reported in table 6 . It was mild in patients with neurological disorders, moderate in patients with structural deficits and high in patients in the general medical diagnostic category. Cramer's V measures were significant for patients with structural deficits $(\mathrm{p}=0.005)$ and patients with general medical diagnoses $(p<0.001)$ but not for patients with neurological disorders $(\mathrm{p}=0.193)$. Figure 1 clearly illus-
Table 7. Relationship between percentages of patient self-perceptions of the location of swallowing difficulties and expert ratings of the videofluorographic studies (VFG) considering three diagnostic categories

\begin{tabular}{|c|c|c|c|c|c|}
\hline Diagnosis & $\begin{array}{l}\text { Location of } \\
\text { swallowing } \\
\text { difficulties }\end{array}$ & $\begin{array}{l}\text { Self- } \\
\text { perception }\end{array}$ & VFG & $\begin{array}{l}\text { Cramer's } \\
\text { V }\end{array}$ & $\begin{array}{l}\text { Prob- } \\
\text { ability }\end{array}$ \\
\hline \multirow[t]{4}{*}{ Neurological } & oral & 0.07 & 0.10 & 0.329 & 0.371 \\
\hline & pharyngeal & 0.43 & 0.63 & & \\
\hline & both & 0.03 & 0.07 & & \\
\hline & no difficulty & 0.47 & 0.20 & & \\
\hline \multirow[t]{4}{*}{ Structural } & oral & 0.04 & 0.08 & 0.509 & 0.028 \\
\hline & pharyngeal & 0.58 & 0.58 & & \\
\hline & both & 0.08 & 0.13 & & \\
\hline & no difficulty & 0.30 & 0.21 & & \\
\hline \multirow[t]{4}{*}{ General } & oral & 0.02 & 0.02 & 0.798 & $<0.001$ \\
\hline & pharyngeal & 0.61 & 0.55 & & \\
\hline & both & 0.02 & 0.06 & & \\
\hline & no difficulty & 0.35 & 0.37 & & \\
\hline
\end{tabular}

trates the differences in correlation among the three medical diagnostic categories. Of the 30 patients with neurological disorders, 13 indicated presence of swallowing problems confirmed by videofluorographic studies and 6 indicated absence of swallowing problems also confirmed by videofluorographic studies. Eleven of the 30 patients showed inconsistency between the self-perception of presence of swallowing problems and the expert rating of the videofluorographic studies. Of the 24 patients with structural deficits, 13 patients indicated presence of swallowing problems confirmed by videofluorographic studies and 6 indicated absence of swallowing problems also confirmed by videofluorographic studies. Five of the 24 patients showed inconsistency between the self-perception of presence of swallowing problems and the expert rating of the videofluorographic studies. Of the 49 patients with general medical diagnoses, 31 patients indicated presence of swallowing problems confirmed by videofluorographic studies and 15 indicated absence of swallowing problems also confirmed by videofluorographic studies. Three of the 49 patients showed inconsistency between the self-perception of presence of swallowing problems and the expert rating of the videofluorographic studies.

The correlation between patient self-perceptions of the location of swallowing difficulties and expert ratings of the videofluorographic studies is reported in table 7. 
Again it was mild in patients with neurological disorders, moderate in patients with structural deficits and high in patients in the general medical diagnostic category. Cramer's $V$ measures were significant for patients with structural deficits $(\mathrm{p}=0.028)$ and patients with general medical diagnoses $(\mathrm{p}<0.001)$ but not for patients with neurological disorders $(\mathrm{p}=0.371)$. Figure 2 illustrates the differences in correlation among the three medical diagnostic categories. Of the 30 patients with neurological disorders, 1 patient indicated oral swallowing problems confirmed by videofluorographic studies, 6 patients indicated pharyngeal swallowing problems confirmed by videofluorographic studies and 3 patients indicated absence of swallowing problems confirmed by videofluorographic studies. Twenty of the 30 patients showed inconsistency between the self-perception of location of swallowing problems and the expert rating of the videofluorographic studies. Of the 24 patients with structural deficits, 10 patients indicated pharyngeal swallowing problems confirmed by videofluorographic studies, 1 patient indicated both oral and pharyngeal swallowing problems confirmed by videofluorographic studies and 5 patients indicated absence of swallowing problems confirmed by videofluorographic studies. Eight of the 24 patients showed inconsistency between the self-perception of location of swallowing problems and the expert rating of the videofluorographic studies. Of the 49 patients with general medical diagnoses, 1 patient indicated oral swallowing problems confirmed by videofluorographic studies, 25 patients indicated pharyngeal swallowing problems confirmed by videofluorographic studies, 1 patient indicated both oral and pharyngeal problems and 15 patients indicated absence of swallowing problems confirmed by videofluorographic studies. Seven of the 49 patients showed inconsistency between the self-perception of location of swallowing problems and the expert rating of the videofluorographic studies.

The correlation between patient self-perceptions of the severity of swallowing difficulties and expert ratings of the videofluorographic studies is reported in table 8 . The same correlation patterns occurred with mild correlation in patients with neurological disorders, moderate correlation in patients with structural deficits and high correlation in patients with general medical diagnoses. Cramer's V measure was significant for patients with general medical diagnoses only $(\mathrm{p}<0.001)$ but not for patients with structural deficits $(\mathrm{p}=0.062)$ and patients with neurological disorders $(\mathrm{p}=0.797)$. Figure 3 illustrates the differences in correlation among the three

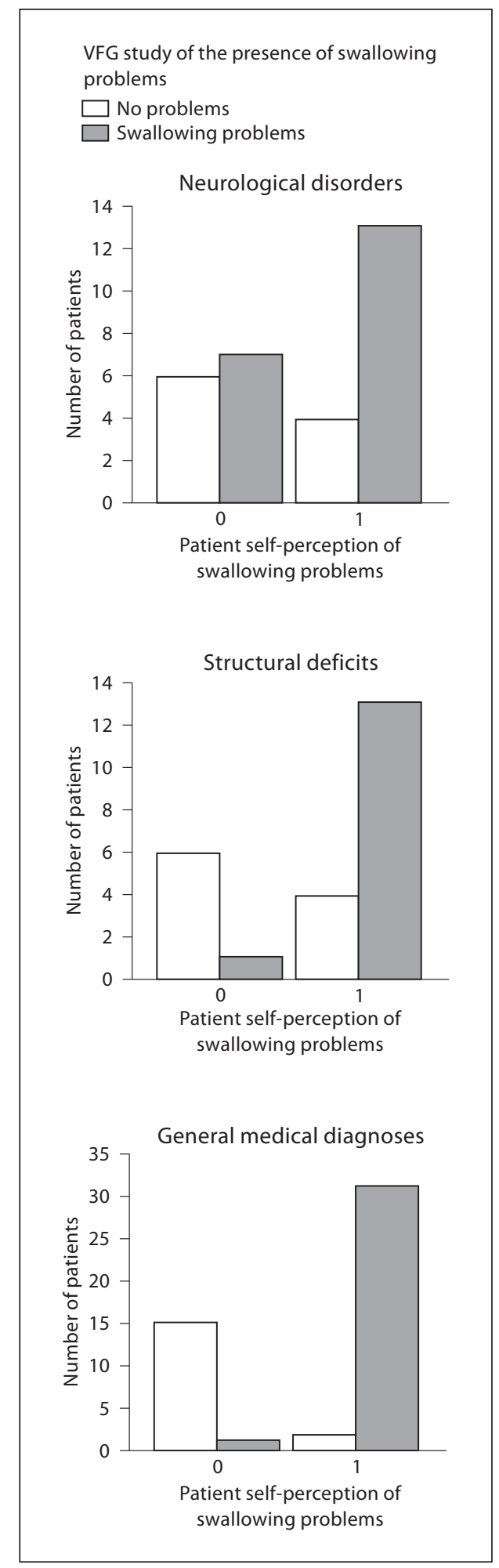

Fig. 1. Clustered bar charts showing the correlation of the number of patients who indicated swallowing difficulties and the expert ratings of videofluorographic (VFG) studies considering the three medical diagnostic categories. Patient self-perception of swallowing problems: $0=$ no problems; $1=$ swallowing problems. 


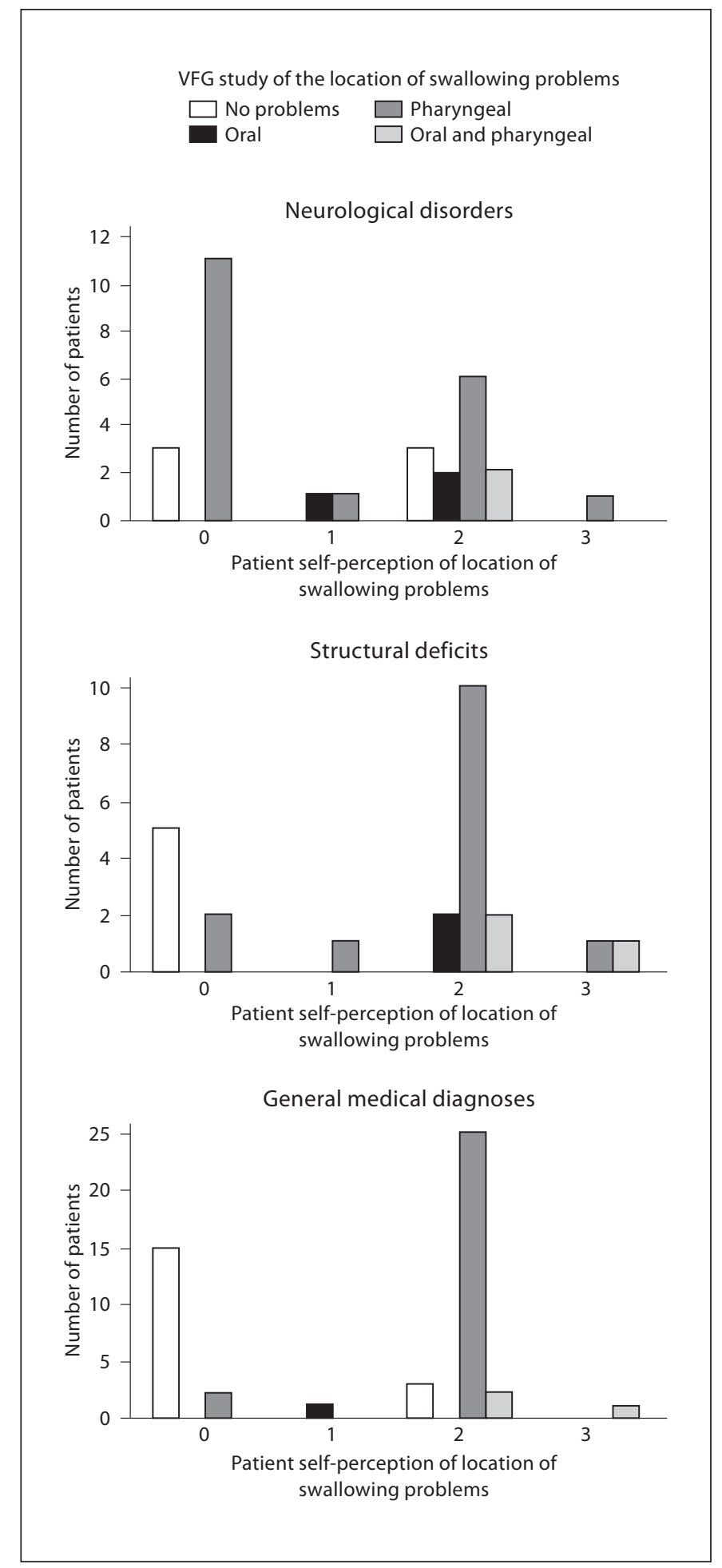

Fig. 2. Clustered bar charts showing the correlation of the number of patients who indicated swallowing problems at various locations and the expert ratings of videofluorographic (VFG) studies considering the three medical diagnostic categories. Patient selfperception of the location of swallowing problems: $0=$ no problems; 1 = oral; 2 = pharyngeal; 3 = oral and pharyngeal.

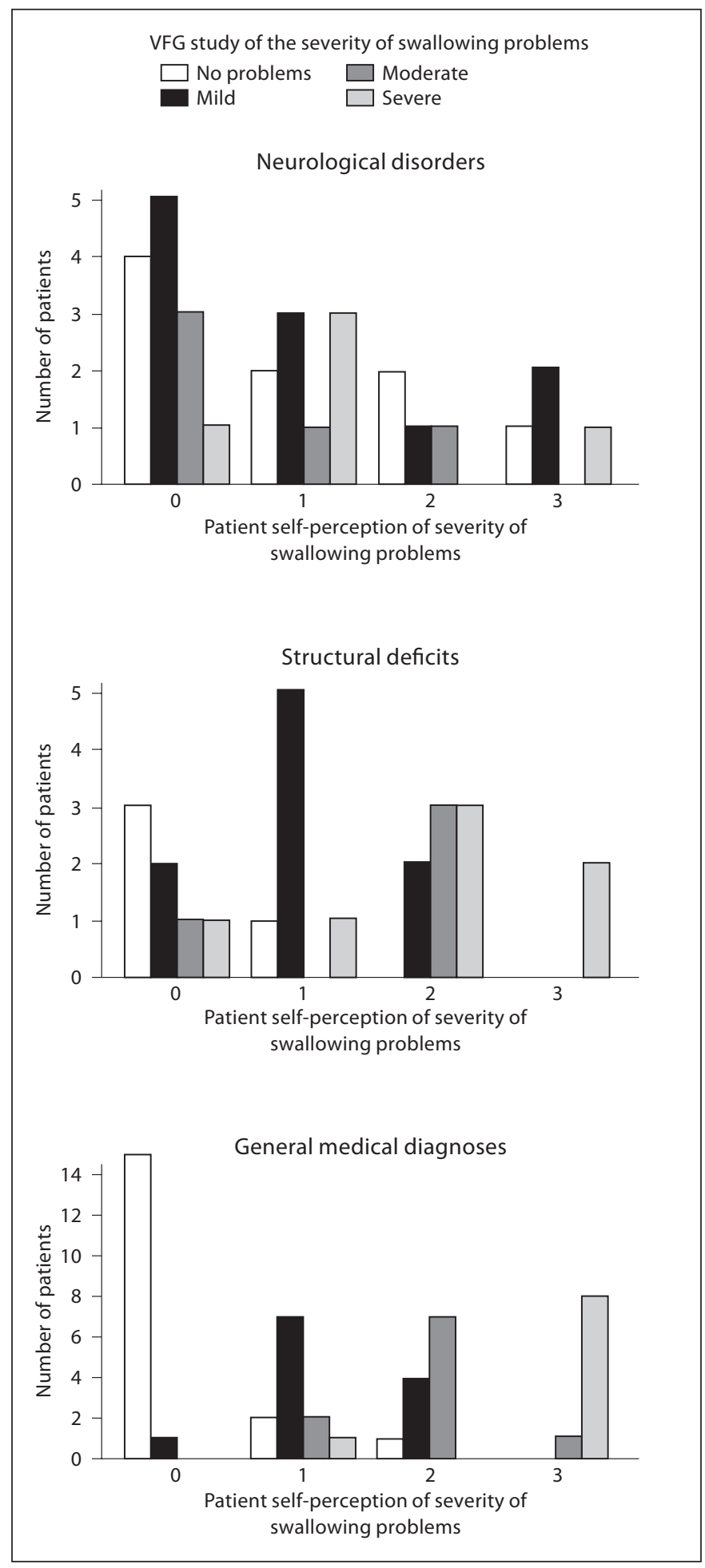

Fig. 3. Clustered bar charts showing the correlation of the number of patients who indicated swallowing problems with various severities and the expert ratings of videofluorographic (VFG) studies considering the three medical diagnostic categories. Patient self-perception of the severity of swallowing problems: $0=$ no problems; 1 = mild; 2 = moderate; $3=$ severe. 
Table 8. Relationship between percentages of patient self-perceptions of the severity of swallowing difficulties and expert ratings of the videofluorographic studies (VFG) considering three diagnostic categories

\begin{tabular}{llllll}
\hline Diagnosis & $\begin{array}{l}\text { Severity of } \\
\text { swallowing } \\
\text { difficulties }\end{array}$ & $\begin{array}{l}\text { Self- } \\
\text { perception }\end{array}$ & VFG & $\begin{array}{l}\text { Cramer's } \\
\text { V }\end{array}$ & $\begin{array}{l}\text { Prob- } \\
\text { ability }\end{array}$ \\
\hline Neurological & mild & 0.30 & 0.37 & 0.245 & 0.797 \\
& moderate & 0.13 & 0.17 & & \\
& severe & 0.13 & 0.17 & & \\
Structural & no difficulty & 0.44 & 0.29 & & \\
& mild & 0.29 & 0.38 & 0.475 & 0.062 \\
& moderate & 0.33 & 0.17 & & \\
General & severe & 0.08 & 0.29 & & \\
& no difficulty & 0.30 & 0.16 & & \\
& mild & 0.24 & 0.24 & 0.710 & $<0.001$ \\
& moderate & 0.24 & 0.20 & & \\
& severe & 0.18 & 0.18 & & \\
& no difficulty & 0.34 & 0.38 & & \\
\hline
\end{tabular}

medical diagnostic categories. Of the 30 patients with neurological disorders, 3 patients indicated mild swallowing problems, 1 patient indicated moderate swallowing problems, 1 patient indicated severe swallowing problems and 4 patients indicated absence of swallowing problems all confirmed by videofluorographic studies. Twenty-one of the 30 patients showed inconsistency between the self-perception of location of swallowing problems and the expert rating of the videofluorographic studies. Of the 24 patients with structural deficits, 5 patients indicated mild swallowing problems, 3 patients indicated moderate swallowing problems, 2 patients indicated severe swallowing problems and 3 patients indicated absence of swallowing problems all confirmed by videofluorographic studies. Eleven of the 24 patients showed inconsistency between the self-perception of location of swallowing problems and the expert rating of the videofluorographic studies. Of the 49 patients with general medical diagnoses, 7 patients indicated mild swallowing problems, 7 patients indicated moderate swallowing problems, 8 patients indicated severe problems and 15 indicated absence of swallowing problems all confirmed by videofluorographic studies. Twelve of the 49 patients showed inconsistency between the self-perception of location of swallowing problems and the expert rating of the videofluorographic studies.

In general, perceptions of patients with general medical diagnoses correlated highly with the expert ratings of videofluorographic studies in identifying the presence, location and severity of swallowing difficulties, followed by perceptions of patients with structural deficits and patients with neurological disorders.

\section{Discussion}

In our study, over $80 \%$ of the patients were noted with swallowing problems during videofluorographic evaluation regardless of medical diagnosis. However, only $54.6 \%$ of the patients noticed swallowing difficulties themselves, which suggests that a significant percentage of patients had no awareness of their swallowing difficulty when they were referred for videofluorographic studies. Previous studies have reported an incidence of swallowing complaints ranging from $16 \%$ in neurological outpatients [12] to $76 \%$ in nasopharyngeal cancer patients [13]. The high percentage of patients in our study who reported swallowing complaints probably reflected the fact that these patients had shown some symptoms of dysphagia, which was the reason they were referred for videofluorographic studies.

The most important finding of the current study is that the correlation between patient self-perceptions of swallowing difficulties and expert ratings of the videofluorographic studies depended greatly on the patient's medical diagnosis. The correlation was mild in patients with neurological disorders, moderate in patients with structural deficits and high in patients with general medical diagnoses.

Patients with neurological disorders showed low correlation with expert ratings of videofluorographic studies in their self-perception of the presence, location and severity of swallowing difficulties in our study. This is consistent with previous studies that have shown that patients with neurological disorders such as stroke and brain tumors were unreliable in identifying the presence of swallow difficulty $[1,4]$. It is possible that these patients have damaged neural connections within the brain or peripherally, which caused inaccurate self-perception of swallowing difficulties.

Patients with structural deficits showed moderate correlation with expert ratings of videofluorographic studies in identifying the presence, location and severity of swallowing difficulties. The moderate correlation is consistent with two previous studies $[2,10]$. After oral and pharyngeal surgery, the correlation between patient selfcomplaints of swallowing difficulties and results of the videofluoroscopic studies was 042-0.57 [10] while in patients diagnosed with Zenker's diverticulum, the correla- 
tion was 0.56 [2]. We hypothesize that the structural deficits in these patients resulted in damaged peripheral sensory nerve endings, thus providing less sensory feedback cues during swallowing.

Patients with general medical diagnoses showed high correlation with expert ratings of videofluorographic studies in identifying the presence, location and severity of swallowing difficulties as compared to patients with either neurological disorders or structural deficits. The swallowing difficulty they experienced is probably due to deconditioning of the whole body, rather than specific deficits of swallowing physiology. The sensory system, including the sensory receptors, peripheral and central sensory pathways seems to be affected the least in this group of patients.

It is imperative to point out that the correlation between patient self-perceptions of swallowing difficulties and expert ratings of the videofluorographic studies was mild to moderate when patients were not divided into three medical diagnostic categories. In clinical settings, patients were frequently referred or not referred for further swallowing evaluation based only on patient selfcomplaints without considering the patient's medical diagnosis. For a patient with neurological disorders, this referral process will be flawed because of the potentially low reliability of the patient's self-perception.

After evaluation, patient self-complaints of swallowing difficulty are often used as a yardstick to measure patient's progress in therapy without confirmation of a videofluoroscopic examination. The results of this study demonstrated that patient self-perceptions of swallowing difficulties should be used judiciously as an indicator for further swallowing evaluation or monitoring progress in therapy in patients with neurological disorders or structural deficits. Patient self-perceptions of swallowing difficulty should be used as one of the criteria, but not the only one, in making referrals for further evaluation or treatment, especially in patients with neurological disorders.

\section{References}

1 Newton HB, Newton C, Pearl D, Davidson T: Swallowing assessment in primary brain tumor patients with dysphagia. Neurology 1994;44:1927-1932.

2 Witterick IJ, Gullane PJ, Yeung E: Outcome analysis of Zenker's diverticulectomy and cricopharyngeal myotomy. Head Neck 1995; 17:382-388.

-3 Balint A, Balazs P, Batorfi J, Fazekas T, Refi M, Ihasz M: Study on dysphagia after proximal selective vagotomy. Acta Chir Hung 1991;32:341-345.

4 Horner J, Massey EW: Silent aspiration following stroke. Neurology 1988;38:317-319.

5 Litvan I, Sastry N, Sonies BC: Characterizing swallowing abnormalities in progressive supranuclear palsy. Neurology 1997;48:16541662 .
Rhodus NL, Colby S, Moller K, Bereuter J: Quantitative assessment of dysphagia in patients with primary and secondary Sjögren's syndrome. Oral Surg Oral Med Oral Pathol Oral Radiol Endod 1995;79:305-310.

-7 Anselmin M, Zaninotto G, Costantini M, et al: Esophageal motor function in primary Sjögren's syndrome: correlation with dysphagia and xerostomia. Dig Dis Sci 1997;42: 113-118

-8 Pauloski BR, Rademaker AW, Logemann JA, Lazarus CL, Newman L, Hamner A, et al: Swallow function and perception of dysphagia in patients with head and neck cancer. Head Neck 2002;24:555-565.
Wright RER, Ellis PK: Patient perception and localization of dysphagia - Barium study correlation. Dis Esophagus 1997;10: 211-214.

10 Baker BM, Fraser AM, Baker CD: Long-term postoperative dysphagia in oral/pharyngeal surgery patients: subjects' perception vs videofluoroscopic observations. Dysphagia 1991;6:11-16.

11 Siegel S, Castellan NJ Jr: Nonparametric Statistics for the Behavioral Sciences. New York, McGraw-Hill, 1988, pp 225-232.

12 Nathadwarawala K, McGroary A, Wiles C: Swallowing in neurological outpatients: use of a timed test. Dysphagia 1994;9:120-129.

13 Hughes PJ, Scott PMJ, Kew J, Cheung DMC, Leung SF, Ahuja AT, Van Hasselt A: Dysphagia in treated nasopharyngeal cancer. Head Neck 2000;22:393-397. 